\title{
Phenotypic and genotypic characterization of Enterococcus cecorum strains associated with infections in poultry
}

\author{
Beata Dolka ${ }^{1 *}$, Dorota Chrobak-Chmiel², László Makrai ${ }^{3}$ and Piotr Szeleszczuk
}

\begin{abstract}
Background: From the beginning of the $21^{\text {st }}$ century Enterococcus cecorum has emerged as a significant health problem for poultry raised under intensive production systems. To obtain new insights into this bacterial species, we investigated 82 clinical isolates originating from different poultry flocks in Poland between 2011 and 2014.

Results: Phenotypically, isolates from clinical cases showed ability to growth at low temperatures $\left(4^{\circ} \mathrm{C}, 10^{\circ} \mathrm{C}\right)$, and differences in growth at $45^{\circ} \mathrm{C}(74.4 \%)$. Survival at high temperatures $\left(60^{\circ} \mathrm{C}, 70^{\circ} \mathrm{C}\right)$ was observed for $15,30 \mathrm{~min}$. More than half of strains survived at $60{ }^{\circ} \mathrm{C}$ even after prolonged incubation $(1 \mathrm{~h})$, but none survived after $1 \mathrm{~h}$ at $70{ }^{\circ} \mathrm{C}$. Total growth inhibition was observed on agar supplemented with tergitol or potassium tellurite. Relatively high number of isolates gave positive reactions for $\beta$-galactosidase ( $\beta G A L ~ 80 \%)$, Voges Proskauer test (60 \%), less for $\beta$-mannosidase (17\%), glycogen and mannitol (12\%). The metabolic fingerprinting for E. cecorum obtained in Biolog system revealed ability to metabolise 22 carbon sources. Only $27 / 82$ strains contained $\geq 1$ virulence genes of tested 7 , however $2.4 \%$ isolates carried 6. Increased antimicrobial resistance was observed to enrofloxacin (87\%), teicoplanin (85\%), doxycycline (83\%), erythromycin (46\%). Most strains (75/82) showed multidrug resistance. The single isolate was resistant to vancomycin (VRE) and high level gentamicin (HLGR). Linezolid resistance among clinical isolates was not found. PFGE revealed diversity of E. cecorum from cases. It could be assumed that transmission of pathogenic strains between flocks regardless of type of production or geographical region may be possible.

Conclusions: Clinical infections in poultry caused by E. cecorum may indicated on new properties of this bacterial species, previously known as a commensal. Despite many common phenotypic features, differences were found among clinical isolates. Several, widely distributed pathogenic E. cecorum strains seemed to be responsible for infection cases found in different poultry types.
\end{abstract}

Keywords: Enterococcus cecorum, Phenotyping, Genotyping, PFGE, Enterococcal spondylitis, Chicken

\section{Background}

First time Enterococcus cecorum was isolated from cecal flora of chickens and described as Streptococcus cecorum in 1983, thereafter well known as commensal in gastrointestinal tract of various mammals and birds [1]. On the other hand, Enterococcus cecorum belongs to opportunistic pathogens and may also play a role as etiological agent of diseases in humans (nosocomial infections) [2, 3], chickens [4], and racing pigeons [5]. Recently, this bacteria appears

\footnotetext{
* Correspondence: beata_dolka@sggw.pl

${ }^{1}$ Department of Pathology and Veterinary Diagnostics, Faculty of Veterinary Medicine, Warsaw University of Life Sciences-SGGW, Nowoursynowska 159c St., Warsaw 02-776, Poland

Full list of author information is available at the end of the article
}

to be a new threat ("emerging pathogen") to poultry industry worldwide [6-15]. E. cecorum has been increasingly recognized as a cause of enterococcal spondylitis (ES), previously called enterococcal vertebral osteoarthritis (EVOA) in chickens [12]. Disease outbreaks were diagnosed mostly in broiler chicken flocks raised under an intensive production system. Clinically affected birds suffered from locomotor problems due to compression of the spinal cord at the thoracic vertebrae resulting from E. cecorum induced osteomyelitis and due to femoral head necrosis (FHN) $[6,7,9,12,13]$. Disease outbreaks can lead to high morbidity, mortality, culling, carcass condemnations, and may result in severe economic losses within a short time [9]. 
Recently, poultry or domestic animals (cats, dogs) are thought to be a possible source for transmission leading to $E$. cecorum-associated septicaemia in humans [2, 3].

Various methods using conventional biochemical tests and molecular techniques have been commonly used for identification and typing enterococci [16-18]. Pulsed field gel electrophoresis (PFGE) is considered to be the "gold standard" for subtyping enterococci and has been used extensively for molecular epidemiological characterization of enterococcal outbreaks $[19,20]$. The PCR assay based on specific amplification followed by sequencing and nucleotide sequence comparison of target genes (such as $16 \mathrm{~S}$ ribosomal RNA, sodA, $d d l$, tuf, groESL) or tDNA-PCR have served for the genotypic identification of enterococci [21-23].

Despite of available literature biochemical and molecular analysis of E. cecorum strains with poultry origin isolated in Europe are still limited. Moreover, there is not enough data regarding the properties of isolates, usually referred as pathogenic for poultry $[1,7,8,10]$. The purpose of this study was phenotypic characterization of clinical E. cecorum isolates associated with infections in poultry and investigation their genetic relatedness.

\section{Methods}

\section{Bacterial isolates}

Eighty two E. cecorum isolates of poultry-origin used in this study were obtained from archival bacterial collection deposited at Department of Pathology and Veterinary Diagnostics, or were obtained from clinical specimens submitted by veterinarians for routine diagnostic work to the Diagnostic Laboratory in Division of Avian Diseases, Faculty of Veterinary Medicine at the Warsaw University of Life Sciences-SGGW (Poland). Authors ensure that the ARRIVE guidelines were followed. Among 82 clinical strains collected between 2011 and 2014, 49 came from broiler chicken flocks (CB), 20 from broiler breeder flocks (BB), 10 from commercial layer flocks (CL), 2 from geese flocks (G) and 1 from turkey flock (T). According to adopted criteria in this study, one E. cecorum isolate represented one different flock in which clinical problems due to $E$. cecorum infection were reported by veterinarians on farms. Affected birds displayed a variety of clinical signs, however in all types of flocks the lameness, paralysis, hock sitting, weakness, pododermatitis, decreased water and food intake were usually noted. Subsequently, disease caused lower results of production, increased losses due to mortality and culling. Necropsies and pathological examinations revealed usually femoral head necrosis, (purulent) arthritis, fibrinous pericarditis, endocarditis, hepatitis and congested lungs. Characteristic osteomyelitis lesions at caudal thoracic vertebrae we found only in chicken flocks (mainly in $\mathrm{CB}$ ). Isolates were recovered from tissue samples such as vertebral column, femoral heads, heart, liver, lungs or yolk sac, which were collected during necropsy.

\section{Bacterial analysis}

The tissue samples were inoculated onto Columbia agar with $5 \%$ sheep blood (CA) (Graso, Poland) and agar plates with esculin (KAA, Biocorp, Poland; Enterococcosel Agar, Graso, Poland), then incubated at $37{ }^{\circ} \mathrm{C}$ for $24 \mathrm{~h}$ in a $\mathrm{CO}_{2}$-enriched atmosphere. Bacteria were identified as Enterococcus based on their phenotypic properties such as colonial morphology, hemolysis (on CA), Gram-staining, catalase production (using a $3 \% \mathrm{H}_{2} \mathrm{O}_{2}$ ), cytochrome oxidase production (OXItest, Erba Lachema s.r.o., Czech Republik), and esculin hydrolysis (Enterococcosel Agar, KAA). Pigment production was visually assayed by growing the bacteria on CA for $24 \mathrm{~h}$ and scraping off the growth with a white cotton swab. Motility was examined using Motility Test Agar (Graso, Poland). The ability to growth was estimated in $6.5 \%$ $\mathrm{NaCl}$ (salt tolerance test) after $48 \mathrm{~h}$ at $37{ }^{\circ} \mathrm{C}$, and on different media (Graso, Poland) (Table 2). Serological identification of Lancefield group was conducted by rapid latex agglutination method using Slidex Strepto Plus D (bioMérieux, France). Tests for E. cecorum growth were performed in BHI broth (Brain-heart infusion; bioMérieux, France) tubes preincubated at $4{ }^{\circ} \mathrm{C}, 10{ }^{\circ} \mathrm{C}$, $45{ }^{\circ} \mathrm{C}$ for $24 \mathrm{~h}$. Then cultures in BHI broth were spread onto $\mathrm{CA}$ and incubated at $37{ }^{\circ} \mathrm{C}$. The growth response was assessed after $24 \mathrm{~h}$ and $48 \mathrm{~h}$. The ability to survive at $60{ }^{\circ} \mathrm{C}, 70{ }^{\circ} \mathrm{C}$ was estimated for $15 \mathrm{~min}$, $30 \mathrm{~min}, 1 \mathrm{~h}$ in BHI broth tubes, followed by incubation of inoculated CA plates. The results were recorded after $24 \mathrm{~h}$ and $48 \mathrm{~h}$.

\section{Biochemical tests}

Identification to the species level based on biochemical characterization was performed by API rapid ID 32 STREP (bioMérieux, France) and on the basis of carbon source utilisation using Biolog system (Biolog Inc., Hayward, USA). Isolates $(n=13)$ were determined according to Biolog GP2 MicroPlates, which performed 95 discrete tests simultaneously and gave a characteristic reaction pattern (metabolic fingerprint). The MicroPlates were incubated at $37{ }^{\circ} \mathrm{C}$ and read visually after $4 \mathrm{~h}$ and $24 \mathrm{~h}$. The metabolic fingerprint patterns were compared and identified using the MicroLog ${ }^{\text {ma }} \quad 4.20 .05$ database software.

\section{Virulence factors}

All 82 isolates were tested for the presence of seven virulence factors: asa1 (aggregation substance), gelE (gelatinase), $h y l$ (hyaluronidase), esp (enterococcal surface protein), cylA (cytolisin), efaA (endocarditis antigen), ace (collagen-binding protein) according to 
Martín-Platero et al. [24], Jung et al. [5] using duplex PCRs (asa1/gelE, cylA/esp, efaA/ace) and single PCR $(h y l)$. PCR reaction mix contained $12.5 \mu \mathrm{l}$ DreamTaq PCR Master Mix (Thermo Fisher Scientific Inc., USA) $0.3 \mu \mathrm{l}$ of each primer $(50 \mathrm{pmol} / \mu \mathrm{l}), 4 \mu \mathrm{l}$ DNA and PCRclean water (added up to a volume of $25 \mu \mathrm{l}$ ). Thermocycler conditions were as follows: initial denaturation at $94{ }^{\circ} \mathrm{C}$ for $5 \mathrm{~min}$, followed by 30 cycles: denaturation at $94{ }^{\circ} \mathrm{C}$ for $1 \mathrm{~min}$, annealing at $56{ }^{\circ} \mathrm{C}$ for $1 \mathrm{~min}\left(55{ }^{\circ} \mathrm{C}\right.$ for efaA/ace), extension at $72^{\circ} \mathrm{C}$ for $1 \mathrm{~min}$, followed by final extension step $72{ }^{\circ} \mathrm{C}$ for $10 \mathrm{~min}$ and a $4{ }^{\circ} \mathrm{C}$ hold. Amplification products $(10 \mu \mathrm{l})$ were analyzed by $1.2 \%$ agarose gel electrophoresis after ethidium bromide staining and visualized under UV light (UVP, USA). A 100-bp DNA ladder (Thermo Fisher Scientific Inc., USA) was used as a molecular size marker.

Production of gelatinase was additionally determined using Difco Nutrient Gelatin (BD, USA) according to the manufacturer's recommendations. The tubes inoculated with E. cecorum ATCC 43198, S. aureus ATCC 25923 (gelatinase positive), E. coli ATCC 25922 (gelatinase negative) and an uninoculated tube were used for quality control testing.

\section{Antibiotic susceptibility}

Susceptibility for 13 antimicrobial agents: amoxicillin/ clavulanic acid (AUG 20/10 $\mu \mathrm{g}$ ), ampicillin (AP $10 \mu \mathrm{g}$ ), penicillin (PG $10 \mu \mathrm{g}$ ), enrofloxacin (ENF $5 \mu \mathrm{g}$ ) tetracycline (TEC $30 \mu \mathrm{g}$ ), nitrofurantoin (NI $300 \mu \mathrm{g}$ ), doxycycline (DXT $30 \mu \mathrm{g})$, chloramphenicol (C $30 \mu \mathrm{g})$, erythromycin (E $15 \mu \mathrm{g})$, teicoplanin ( $\mathrm{T} 30 \mu \mathrm{g})$, vancomycin (VA $30 \mu \mathrm{g}$ ), high level gentamicin (GM $120 \mu \mathrm{g}$ ) and linezolid (LZD $30 \mu \mathrm{g}$ ) was tested by Kirby-Bauer disk diffusion method and the results were interpreted according to Clinical and Laboratory Standards Institute guidelines [25]. The criteria for selection of antibiotics based on CLSI guidelines for Enterococcus spp. and on their practical significance for the clinical use. Among tested antibiotics, tetracycline, doxycycline, amoxicillin, enrofloxacin have been actually approved for use in poultry (erythromycin until 2014) and have practical relevance. Vancomycin resistance genes (van $\mathrm{A}, \operatorname{van} \mathrm{B})$ were tested by PCR using primers and conditions previously reported [24]. Staphylococcus aureus ATCC 25923 (vancomycin susceptible), E. faecalis ATCC 51299 (vancomycin resistant), E. cecorum ATCC 43198 were used as controls.

\section{Molecular identification}

Rapid extraction of bacterial genomic DNA was carried out by using boiling method. PCR assay targeting $\operatorname{sodA}$ gene was performed for identification and determination the diversity of 82 E. cecorum strains [22]. PCR products were visualized after electrophoresis on agarose gel $(2 \%)$ by staining with ethidium bromide, then purified using GeneMATRIX PCR/DNA Clean-Up Purification Kit (EURx, Poland) and submitted for sequencing to commercial services (IBB PAN, Genomed, Poland). The sodA gene sequences were analyzed with NCBI BLAST. The genetic distances based on the partial sequences of $\operatorname{sodA}$ was calculated by the two-parameter method of Kimura by using the MEGA6, and the phylogenetic tree was constructed using the Neighbor-Joining method (NJ) with 1000 bootstrap replicates.

\section{PFGE}

The standard PFGE procedure was adapted from previously published studies with minor modifications $[18,26,27]$. The 82 E. cecorum strains were cultured overnight on CA and then suspended in sterile saline to obtain the density of 3.5 on McFarland scale and centrifuged $10 \mathrm{~min}$. at $4000 \mathrm{rpm} / \mathrm{min}$. The bacterial pellets were mixed with $150 \mu \mathrm{l}$ Tris-EDTA buffer solution (10 mM Tris- $\mathrm{HCl}, 1 \mathrm{mM}$ disodium EDTA, $\mathrm{pH}$ 8.0) and $150 \mu \mathrm{l}$ liquid $2 \%$ agarose (InCert Agarose, Lonza, Rockland, USA) and small discs were formed $(20 \mu \mathrm{l})$. The solidified discs were incubated at $37^{\circ} \mathrm{C}$ for $18 \mathrm{~h}$ in $1 \mathrm{ml}$ of EC buffer (6 mM Tris- $\mathrm{HCl} \mathrm{pH} 8.0,1 \mathrm{M} \mathrm{NaCl}, 0.1 \mathrm{M}$ EDTA, $0.2 \%$ deoxycholate, $0.2 \%$ sarkosyl) containing $10 \mathrm{mg}$ lysozyme (A\&A Biotechnology, Poland), and $0.02 \mathrm{mg}$ RNase A (Thermo Fisher Scientific Inc., USA). DNA discs were washed 3 times in $5 \mathrm{ml}$ EBS solution (0.5 M EDTA pH 9.0, 1 \% sarkosyl) and incubated overnight at $50{ }^{\circ} \mathrm{C}$ in $1 \mathrm{ml}$ EBS solution containing $1 \mathrm{mg}$ of proteinase K (ESP buffer) (A\&A Biotechnology, Poland). Then the discs were washed 4 times (each time upside down for 30 times at room temperature) with $10 \mathrm{ml} \mathrm{TE}$ buffer (10 mM Tris, $1 \mathrm{mM}$ EDTA, pH 8.0) and stored in $1 \mathrm{ml}$ TE buffer at $4{ }^{\circ} \mathrm{C}$. Subsequently, each disc was preincubated in $100 \mu \mathrm{l}$ restriction buffer for $30 \mathrm{~min}$ at room temperature. The agarose discs were digested with $S m a \mathrm{I}$ $\left(20 \mathrm{U} / \mu \mathrm{l}\right.$; Fermentas, Lithuania) overnight (at $\left.37{ }^{\circ} \mathrm{C}\right)$. The restriction fragments were separated by clamped homogenous electric field (CHEF) electrophoresis with a CHEF-DR II System (Bio-Rad Laboratories, USA) in a $1.2 \%(\mathrm{w} / \mathrm{v})$ agarose gel using pulse time at $0.5 \mathrm{~s}$ followed by $35 \mathrm{~s}$ at $6 \mathrm{~V} / \mathrm{cm}$ and temperature $14{ }^{\circ} \mathrm{C}$ for $24 \mathrm{~h}$ [17]. Afterwards the gel was stained with ethidium bromide for $30 \mathrm{~min}$, then washed in distilled water for $30 \mathrm{~min}$, photographed under UV light and documented in the system VersaDoc (Bio-Rad Laboratories, USA). Lambda Ladder PFG marker (New England Biolabs Inc., USA) was used as molecular size marker. Gel images were analyzed by Gel Compar II version 6.6 (Applied Maths, Belgium) and cluster analysis was performed by UPGMA using dice similarity coefficient with optimization set at $1 \%$ and position tolerance at $1 \%$. Isolates were clustered using an $80 \%$ homology cut-off, above which 
strains were considered to be closely related and assigned to the same PFGE type [19].

\section{Results}

\section{Phenotypic characterization}

Table 1 shows results of conventional tests and effects of different temperatures on the growth and survival of $E$. cecorum strains. Bacterial growth was characterized on 7 different microbiological media (Table 2).

\section{Biochemical tests}

The strains were identified as E. cecorum with the API rapid ID 32 STREP and Biolog system. API revealed perfect identification profile (ID $99.9 \%, \mathrm{~T}$ 0.83) for 40 (49 \%) E. cecorum strains, very good identification (ID $99.9 \%, \mathrm{~T} 0.67)$ for 21 (26\%) strains, good identification (ID $99.8 \%$, T 0.38 ) for 2 (2 \%) strains, doubtful profile (99.9\%, T 0.4) for $16(20 \%)$ strains, and unacceptable profile for $3(4 \%)$ strains. Among perfect identification profiles for E. cecorum, the code 6717-4607-131 was recorded the most often. Based on the analysis of $82 \mathrm{ob}-$ tained profiles in API (each with 32 tests), we defined one common code 2317-4607-111 for clinical strains which gives perfect identification as E. cecorum with the API database. Biochemical results obtained in API were presented in Table 3. The vast majority of isolates was

Table 1 Test or characteristic for E. cecorum isolates $(n=82)$

\begin{tabular}{ll}
\hline Test or characteristic & E. cecorum isolates from clinical cases \\
\hline Hemolysis & a (strong) \\
Gram-staining & Gram-positive \\
Cell morphology & ovoid cocci (single, double or short chains) \\
Catalase-production & negative \\
Oxidase-production & negative \\
Yellow pigment-production & negative \\
Lancefield group D & negative \\
Motility & negative \\
Halotolerance (6.5 \% NaCl) & limited growth \\
Growth at: & $\%$ positive (n) \\
$4{ }^{\circ} \mathrm{C}$ & $100 \%(82)$ \\
$10{ }^{\circ} \mathrm{C}$ & $98.8 \%(81)$ \\
$45{ }^{\circ} \mathrm{C}$ & $74.4 \%(61)$ \\
Survival at $60{ }^{\circ} \mathrm{C}$ for: & $\%$ positive (n) \\
15 min & $76.8 \%(63)$ \\
30 min & $64.6 \%(53)$ \\
$1 \mathrm{~h}$ & $54.9 \%(45)$ \\
Survival at $70{ }^{\circ} \mathrm{C}$ for: & $\%$ positive (n) \\
15 min & $36.6 \%(30)$ \\
30 min & $15.9 \%(13)$ \\
1 h & $0 \%(0)$ \\
\hline
\end{tabular}

positive in tests for $\beta$ GLU, RAF, SAC, M $\beta D G$, CDEX (100 \%), $\alpha$ GAL, RIB, TRE (99 \%), MAL, MEL (98 \%). All isolates were completely negative for ADH, APPA, HIP, PYRA, LARA. The discrepancies among tested and control isolates or recommendations for E. cecorum were noted in 6 tests: $\beta$ GAR, MAN, VP, $\beta$ GAL, GLYG, BMAN.

All of examined isolates were identified as E. cecorum in Biolog system (index: probability $91.7 \%$, similarity 0.806 ). The metabolic fingerprinting for E. cecorum was showed in Fig. 1. All of the examined isolates were able to metabolise 22 carbon sources ( $\alpha$-cyclodextrin, dextrin, $\mathrm{N}$ acetyl-D-glucosamine, N-acetyl-D-mannosamine, arbutin, D-cellobiose, D-fructose, D-galactose, gentiobiose, $\alpha$-Dglucose, maltose, maltotriose, D-mannose, D-melibiose, D-psicose, D-raffinose, salicin, stachyose, sucrose, Dtrehalose, pyruvic acid methyl ester, adenosine). Not all of examined isolates were able to metabolise 14 carbon sources: amygdalin, D-melezitose, $\beta$-methyl-D-glucoside, inosine, thymidine, uridine (metabolised by $92.3 \%$ strains), $\alpha$-D-lactose (84.6\%), D-ribose (76.9\%), lactulose, palatinose (69.2 \%), 2'-deoxy-adenosine (61.5 \%), adenosine-5'-monophosphate, uridine-5'-monophosphate (53.8 \%), $\beta$-methyl-D-galactoside (15.4\%). Further 59 carbon sources present in the GP2 microplate were not utilised by E. cecorum.

\section{Virulence factors}

Of all 82 E. cecorum strains, $22(26.8 \%)$ were positive for asa1, 21 (25.6 \%) for gelE, 12 (14.6\%) for ace, 11 (13.4 \%) for efaA. The cylA and esp PCR amplification yielded positive results in $4(4.9 \%)$ and $2(2.4 \%) E$. cecorum strains. The hyl gene was not detected in any strain. The isolates from $\mathrm{CB}$ were positive for asa1 (24.5\%), gelE (22.4\%), ace (14.3\%), efaA (14.3\%), cylA $(2.1 \%)$. The isolates from $\mathrm{BB}$ were positive for asa1 (20\%), gelE (20\%), ace (15\%), esp (10\%), cylA (10\%). The isolates from CL were positive for asa1 (60\%), gelE $(60 \%)$, efaA (20\%), ace (20\%). None of 7 virulence factors was found in isolates from $\mathrm{G}$ and $\mathrm{T}$ flocks. Most of virulence-gene positive isolates $(11 ; 13.4 \%)$ contained 2 of tested 7 virulence genes, then $6(7.3 \%)$ E. cecorum contained 4 virulence genes, 5 (6.1\%) harbored 1 virulence gene, while $3(3.7 \%)$ carried 3 virulence genes. In two isolates $(2.4 \%) 6$ virulence genes were identified. None of isolates carried 5 or 7 virulence genes. Phenotypically, non of isolates produced gelatinase despite being gelE-positive in PCR.

\section{Antibiotic susceptibility}

One $(0.82 \%)$ out of the 82 clinical E. cecorum was susceptible to 13 antibiotics tested, the rest were resistant to one or more antibiotics (Table 4). All isolates were susceptible to amoxicillin/clavulanic acid (AUG) and 
Table 2 Results of $E$. cecorum $(n=82)$ growth on different media

\begin{tabular}{|c|c|c|}
\hline Medium & Observed growth (YES/NO) & Description of colonies of Enterococcus cecorum \\
\hline Columbia Agar with 5 \% Sheep Blood (CA) & YES & Small, round, white-grey colonies with a-hemolysis \\
\hline Columbia CNA Agar with $5 \%$ Sheep Blood & YES & $\begin{array}{l}\text { Small, grayish colonies with a-hemolysis, resistant to two antibiotics } \\
\text { colistin and nalidixic acid }\end{array}$ \\
\hline Edwards Agar with $5 \%$ sheep blood & YES & Blue-grayish coloured colonies with a-hemolysis \\
\hline Bile Esculin Azide Agar (Enterococcosel Agar) & YES & Colonies beige with strong black halos \\
\hline KAA agar (Kanamycine Esculin Azide Agar) & YES (weak) & Brown to black colonies and blackening zones around the colonies \\
\hline Slanetz and Bartley Agar (with tetrazolium chloride) & NO or poor & Red, maroon colonies \\
\hline TCC agar with tergitol & NO & Total inhibition \\
\hline Tellurite Agar (potassium tellurite) & NO & Total inhibition \\
\hline
\end{tabular}

penicillin (PG), nitrofurantoin (NI), and linezolid (LZD). The majority of isolates were susceptible to ampicillin (AP), and high level gentamicin (GM) $(n=81 ; 99 \%)$, chloramphenicol (C) ( $n=79 ; 96 \%)$, vancomycin (VA) ( $n$ $=75 ; 91 \%)$. The lower level susceptibility was to erythromycin (E) $(n=42 ; 51 \%)$, tetracycline (TEC) $(n=$ 24; $29 \%)$, teicoplanin (T) and doxycycline (DXT) $(n=$ $11 ; 13 \%)$. Most isolates noted intermediate susceptibility to TEC ( $n=53$; $65 \%)$ with $29 \%$ susceptible and $6 \%$ resistant. None of clinical E. cecorum isolates was susceptible to enrofloxacin (71 resistant isolates). A high percentage of antimicrobial resistance was also observed to teicoplanin (T) $(n=70 ; 85 \%)$, and doxycycline (DXT) $(n=68 ; 83 \%)$. Linezolid resistance among E. cecorum isolates was not found. Of the vancomycin resistance genes tested by PCR, vanA gene was present in one strain, $v a n B$ gene was not detected.

\section{Molecular identification}

The obtained sequences sodA gene fragment showed similarity to E. cecorum (BLAST database) and allowed for identification strains. Dendrogram showed the genetic similarity between reference strain of E. cecorum and clinical isolates based on the $\operatorname{sodA}$ gene sequences (Fig. 2). Phylogenetic analysis supported the separation of clinical isolates into three main groups (A, B, C). Genetic distances between groups ranged from 0.00 to 0.04 (Table 5). The group A comprised 69 strains (CB $n$ $=43, \mathrm{BB} n=15, \mathrm{CL} n=10, \mathrm{G} n=1)$ and had one subgroup (A') with 5 strains (BB $n=4, \mathrm{CB} n=1$ ). Five $\mathrm{CB}$ isolates were clustered together in the group $\mathrm{B}$, and three isolates $(\mathrm{BB}, \mathrm{G}, \mathrm{T}$ ) in the group $\mathrm{C}$ (all isolates from 2014). Among all groups, the group $C$ revealed the highest values of genetic distance with B group (0.04) and with reference strain $(0.03)$.

\section{PFGE}

The PFGE analysis (based on $>80 \%$ similarity index) of 82 clinical E. cecorum isolates exhibited 21 pulsotypes (A-U) with 60 strains $(41 \mathrm{CB}, 10 \mathrm{BB}, 8 \mathrm{CL}, 1 \mathrm{G}$ ) (Table 6,
Fig. 3). The highest degree of band similarity (>90\%) was demonstrated in pulsotype $\mathrm{B}$ (with two $\mathrm{CB}$ isolates) and in pulsotype $S$ (with $\mathrm{G}$ and $\mathrm{CB}$ isolate). Pulsotype $\mathrm{M}$ was the predominant type, and included 8 isolates $(8 / 60$, $13.3 \%$ ), then $\mathrm{E}, \mathrm{L}, \mathrm{T}$ pulsotypes (each included 4 isolates). However, 11 of the 21 pulsotypes included only 2 isolates. Twenty isolates $(20 / 60,33.3 \%)$ representing CB flocks (20/41; $48.8 \%$ ), were distributed among 8 pulsotypes: A, B, C, D, P (each $3.33 \%$ ), F, K (each $5 \%$ ), L (6.6\%). The majority of $\mathrm{BB}$ isolates $(7 / 10,70 \%)$ were clustered with $\mathrm{CB}$ isolates (13) in distinct 6 pulsotypes (E, G, I, M, Q, R). Among isolates representing CL flocks $(8 / 60,13.3 \%)$, three of these $(3 / 8,37.5 \%)$ were clustered in one profile $(\mathrm{L})$. Three pulsotypes $(\mathrm{H}, \mathrm{N}, \mathrm{O})$ were created by clustering both CB (5) and CL (3) isolates. Generally, no clear temporal and geographical clustering was visible, but with the exceptions of 7 pulsotypes (A, D, I, L, M, P, U).

\section{Discussion}

In order to characterize clinical E. cecorum, we investigated 82 strains isolated from clinical samples originated from different poultry flocks (1 isolate per flock). Our observations were consistent with reports on a succession of disease outbreaks in broiler flocks raised in the intensive farming systems [9]. Previously, clinical E. cecorum was not described in commercial chicken layers or geese flocks. We found that the problem may affect hens or other bird species than chicken. Our results were consistent with the literature in regarding on certain characteristics traditionally considered to be typical for the genus Enterococcus or E. cecorum including intestinal isolates of poultry origin $[28,29]$. According to the literature, $E$. cecorum are often $\mathrm{NaCl}$ sensitive $[17,30]$, and intestinal $E$. cecorum of poultry may be also NaCl-resistant [28]. In our study, clinical isolates appeared to be less salt-tolerant, however no complete inhibition of growth was observed. Authors suggested possible higher ability to survive clinical $E$. cecorum in saline environment or even higher resistance to chlorine-based disinfectants. 
Table 3 Percent of positive reactions (\%) in rapid ID 32 STREP (bioMérieux, France) for clinical E. cecorum isolates in this study ( $n=82)$ compared with standard isolates (manufacturers recommendations) and control strain (E. cecorum ATCC 43198)

\begin{tabular}{|c|c|c|c|}
\hline \multirow[t]{2}{*}{ Parameter } & \multicolumn{3}{|c|}{ \% Positive reactions in rapid ID 32 STREP for Enterococcus cecorum } \\
\hline & Clinical isolates (this study) \% (n) & Manufacturers recommendations $\%$ & Reference strain E. cecorum ATCC 43198 (+/-) \\
\hline $\mathrm{ADH}$ & $0(0)$ & 0 & - \\
\hline$\beta G L U$ & $100(82)$ & 100 & + \\
\hline$\beta G A R$ & $73(60)$ & 11 & - \\
\hline$\beta G U R$ & $94(77)$ & 88 & + \\
\hline aGAL & $99(81)$ & 100 & + \\
\hline PAL & $71(58)$ & 94 & + \\
\hline $\mathrm{RIB}$ & $99(81)$ & 98 & + \\
\hline MAN & $12(10)$ & 38 & - \\
\hline SOR & $10(8)$ & 11 & - \\
\hline LAC & $88(72)$ & 100 & + \\
\hline TRE & $99(81)$ & 100 & + \\
\hline RAF & $100(82)$ & 88 & + \\
\hline VP & $60(49)$ & 66 & - \\
\hline APPA & $0(0)$ & 0 & - \\
\hline$\beta G A L$ & $80(66)$ & 33 & - \\
\hline PYRA & $0(0)$ & 0 & - \\
\hline$\beta N A G$ & $82(67)$ & 88 & + \\
\hline GTA & 89 (73) & 94 & + \\
\hline HIP & $0(0)$ & 1 & - \\
\hline GLYG & $12(10)$ & 27 & - \\
\hline PUL & $4(3)$ & 0 & - \\
\hline MAL & $98(80)$ & 100 & + \\
\hline MEL & $98(80)$ & 98 & + \\
\hline MLZ & $88(72)$ & 55 & + \\
\hline SAC & $100(82)$ & 100 & + \\
\hline LARA & $0(0)$ & 0 & - \\
\hline DARL & $1(1)$ & 0 & - \\
\hline$M \beta D G$ & $100(82)$ & 98 & + \\
\hline TAG & $65(53)$ & 64 & + \\
\hline BMAN & $17(14)$ & 41 & - \\
\hline CDEX & $100(82)$ & 66 & + \\
\hline URE & $6(5)$ & 0 & - \\
\hline
\end{tabular}

ADH (arginine dihydrolase), $\beta G L U$ ( $\beta$-glucosidase), $\beta G A R$ ( $\beta$-galactosidase), $\beta G U R$ ( $\beta$-glucuronidase), aGAL (a-galactosidase), PAL (alkaline phosphatase), RIB (ribose), MAN (mannitol), SOR (sorbitol), LAC (lactose), TRE (trehalose), RAF (rafinose), VP (Voges Proskauer, aceton production), APPA (alanyl-phenylalanyl-proline arylamidase), $\beta$ GAL ( $\beta$-galactosidase), PYRA (pyroglutamic acid arylamidase), $\beta N A G$ (N-acetyl- $\beta$-glucosaminidase), GTA (glycyl-tryptophan arylamidase), HIP (hydrolysis of hipurate), GLYG (glycogen), PUL (pullulane), MAL (maltose), MEL (melibiose), MLZ (melezitose), SAC (saccharose), LARA (L-arabinose), DARL (D-arabitol), CDEX (cyclodextrin), MßDG (methyl- $\beta$ D-glucopyranoside), TAG (tagatose), $\beta$ MAN ( $\beta$-mannosidase), URE (urease)

Previous research demonstrated no growth of poultry cecal E. cecorum on Slanetz medium, and on KAA agar [1], while clinical strains showed variable growth on these media. The growth was clearly more abundant on bile esculine azide agar than on esculin azide agar with kanamycin. Based on results, we suggested that complete growth inhibition on a solid medium supplemented with tergitol or with potassium tellurite may be used in identification of this enterococcal species. According to the literature, Enterococcus species are able to survive a range of stresses and hostile environments [31], but $E$. cecorum was described as unable to grow at $10{ }^{\circ} \mathrm{C}$ or survive $30 \mathrm{~min}$ at $60{ }^{\circ} \mathrm{C}[5,29]$. In contrast to above authors, clinical isolates were able to grow at low temperatures $\left(4{ }^{\circ} \mathrm{C}, 10{ }^{\circ} \mathrm{C}\right)$ and some of them might survive even longer heating at $60{ }^{\circ} \mathrm{C}$ for $1 \mathrm{~h}$ and even $70{ }^{\circ} \mathrm{C}$ for 


\begin{tabular}{|c|c|c|c|c|c|c|c|c|c|c|c|c|}
\hline & 1 & 2 & 3 & 4 & 5 & 6 & 7 & 8 & 9 & \begin{tabular}{|l|}
10 \\
\end{tabular} & \begin{tabular}{|l|}
11 \\
\end{tabular} & 12 \\
\hline$A$ & \begin{tabular}{|l} 
A1 \\
Water \\
(Control)
\end{tabular} & \begin{tabular}{|l|} 
A2 \\
$\alpha--$ \\
Cyclodextrin \\
$(100 \%)$ \\
\end{tabular} & \begin{tabular}{|l|}
$\mathrm{A} 3$ \\
$\beta$-Cyclodextrin \\
$(\mathbf{0} \%)$
\end{tabular} & \begin{tabular}{|l|} 
A4 \\
Dextrin \\
$(100 \%)$
\end{tabular} & \begin{tabular}{|l} 
A5 \\
Glycogen \\
$(0 \%)$
\end{tabular} & \begin{tabular}{|l|} 
A6 \\
Inulin \\
$(0 \%)$
\end{tabular} & $\begin{array}{l}\text { A7 } \\
\text { Mannan } \\
(0 \%)\end{array}$ & \begin{tabular}{|l|} 
A8 \\
Tween 40 \\
$(0 \%)$
\end{tabular} & \begin{tabular}{|l} 
A9 \\
Tween 80 \\
$(0 \%)$
\end{tabular} & \begin{tabular}{|l|} 
A10 \\
N-Acetyl-D- \\
Glucosamine \\
$(100 \%)$
\end{tabular} & $\begin{array}{l}\text { A11 } \\
\text { N-AcetylD- } \\
\text { Mannosamine } \\
(100 \%)\end{array}$ & \begin{tabular}{|l|} 
A12 \\
Amygdalin \\
$(92.3 \%)$
\end{tabular} \\
\hline B & $\begin{array}{l}\text { B1 } \\
\text { L-Arabinose } \\
(0 \%)\end{array}$ & $\begin{array}{l}\text { B2 } \\
\text { D-Arabitol } \\
(0 \%)\end{array}$ & $\begin{array}{l}\text { B3 } \\
\text { Arbutin } \\
(100 \%)\end{array}$ & \begin{tabular}{|l|} 
B4 \\
D-Cellobiose \\
$(100 \%)$
\end{tabular} & \begin{tabular}{|l|} 
B5 \\
D-Fructose \\
(100\%)
\end{tabular} & \begin{tabular}{|l}
$\mathrm{B} 6$ \\
$\mathrm{~L}-$-Fucose \\
$(0 \%)$
\end{tabular} & $\begin{array}{l}\text { B7 } \\
\text { D-Galactose } \\
(100 \%)\end{array}$ & \begin{tabular}{|l|}
$\mathrm{B} 8$ \\
$\mathrm{D}-$ Galacturonic \\
Acid $(0 \%)$
\end{tabular} & $\begin{array}{l}\text { B9 } \\
\text { Gentiobiose } \\
(100 \%)\end{array}$ & $\begin{array}{l}\text { B10 } \\
\text { D-Gluconic } \\
\text { Acid ( } 0 \%)\end{array}$ & $\begin{array}{l}\text { B11 } \\
\alpha \text {-D-Glucose } \\
(100 \%)\end{array}$ & \begin{tabular}{|l} 
B12 \\
m-Inositol \\
$(0 \%)$
\end{tabular} \\
\hline C & $\begin{array}{l}\text { C1 } \\
\text { a-D-Lactose } \\
(84.6 \%)\end{array}$ & \begin{tabular}{|l}
$\mathrm{C} 2$ \\
Lactulose \\
$(69.2 \%)$
\end{tabular} & $\begin{array}{l}\text { C3 } \\
\text { Maltose } \\
(100 \%)\end{array}$ & $\begin{array}{l}\text { C4 } \\
\text { Maltotriose } \\
(100 \%)\end{array}$ & \begin{tabular}{|l|} 
C5 \\
D-Mannitol \\
$(0 \%)$
\end{tabular} & $\begin{array}{l}\text { C6 } \\
\text { D-Mannose } \\
(100 \%)\end{array}$ & $\begin{array}{l}\text { C7 } \\
\text { D-Melez itose } \\
(92.3 \%)\end{array}$ & $\begin{array}{l}\text { C8 } \\
\text { D-Melibiose } \\
(100 \%)\end{array}$ & $\begin{array}{l}\text { C9 } \\
\text { a-Methyl- } \\
\text {-D- } \\
\text { Galactoside } \\
(0 \%)\end{array}$ & $\begin{array}{l}\text { C10 } \\
\beta \text {-Methyl- } \\
\text {-D- } \\
\text { Galactoside } \\
(15.4 \%)\end{array}$ & $\begin{array}{l}\text { C11 } \\
\text { 3-Methyl-D- } \\
\text { Glucose } \\
(0 \%)\end{array}$ & $\begin{array}{l}\text { C12 } \\
\text { o-Methyl-D- } \\
\text { Glucoside } \\
(0 \%)\end{array}$ \\
\hline $\mathrm{D}$ & \begin{tabular}{|l|} 
D1 \\
$\beta$-Methyl-D- \\
Glucoside \\
$(92.3 \%)$ \\
\end{tabular} & \begin{tabular}{|l|} 
D2 \\
o-Methyl-D- \\
Mannoside \\
$(0 \%)$ \\
\end{tabular} & \begin{tabular}{|l} 
D3 \\
Palatinose \\
$(69.2 \%)$
\end{tabular} & \begin{tabular}{|l} 
D4 \\
D-Psicose \\
$(100 \%)$
\end{tabular} & \begin{tabular}{|l|} 
D5 \\
D-Raffinose \\
$(100 \%)$
\end{tabular} & $\begin{array}{l}\text { D6 } \\
\text { L-Rhamnose } \\
(0 \%)\end{array}$ & \begin{tabular}{|l|} 
D7 \\
D-Ribose \\
$(76.9 \%)$
\end{tabular} & \begin{tabular}{|l|} 
D8 \\
Salicin \\
$(100 \%)$
\end{tabular} & \begin{tabular}{|l|} 
D9 \\
Sedoheptulos \\
an \\
$(0 \%)$ \\
\end{tabular} & \begin{tabular}{|l} 
D10 \\
D-Sorbitol \\
$(0 \%)$
\end{tabular} & \begin{tabular}{|l} 
D11 \\
Stachyose \\
$(100 \%)$
\end{tabular} & \begin{tabular}{|l|} 
D12 \\
Sucrose \\
$(100 \%)$
\end{tabular} \\
\hline $\mathrm{E}$ & \begin{tabular}{|l} 
E1 \\
D-Tagatose \\
$(0 \%)$
\end{tabular} & \begin{tabular}{|l|} 
E2 \\
D-Trehalose \\
$(100 \%)$
\end{tabular} & \begin{tabular}{|l|} 
E3 \\
Turanose \\
$(0 \%)$
\end{tabular} & \begin{tabular}{|l|} 
E4 \\
Xylitol \\
$(0 \%)$
\end{tabular} & \begin{tabular}{|l|} 
E5 \\
D-Xylose \\
$(0 \%)$
\end{tabular} & \begin{tabular}{|l|} 
E6 \\
Acetic Acid \\
$(0 \%)$
\end{tabular} & \begin{tabular}{|l|} 
E7 \\
a- \\
Hydroxybutyric \\
Acid $(0 \%)$
\end{tabular} & \begin{tabular}{|l|} 
E8 \\
$\beta-$ \\
Hydroxybutyri \\
c Acid $(0 \%)$
\end{tabular} & \begin{tabular}{|l|} 
E9 \\
$\gamma-$ \\
Hydroxybutyr \\
ic Acid $(0 \%)$ \\
\end{tabular} & \begin{tabular}{|l|} 
E10 \\
p-Hydr oxy \\
Phenyl Acetic \\
Acid $(0 \%)$ \\
\end{tabular} & $\begin{array}{l}\text { E11 } \\
\alpha- \\
\text { Ketoglutaric } \\
\text { Acid }(0 \%) \\
\end{array}$ & \begin{tabular}{|l|} 
E12 \\
$\alpha--$ \\
Ketovaleric \\
Acid $(0 \%)$ \\
\end{tabular} \\
\hline$F$ & \begin{tabular}{|l|} 
F1 \\
Lactamide \\
$(0 \%)$
\end{tabular} & \begin{tabular}{|l|} 
F2 \\
D-Lactic \\
Acid \\
MethylEster \\
$(0 \%)$ \\
\end{tabular} & \begin{tabular}{|l|} 
F3 \\
L-Lactic Acid \\
$(0 \%)$
\end{tabular} & \begin{tabular}{l|} 
F4 \\
D-Malic Acid \\
$(0 \%)$
\end{tabular} & \begin{tabular}{|l|} 
F5 \\
L-Malic \\
Acid \\
$(0 \%)$ \\
\end{tabular} & $\begin{array}{l}\text { F6 } \\
\text { Pyruvic Acid } \\
\text { MethylEster } \\
(100 \%)\end{array}$ & $\begin{array}{l}\text { F7 } \\
\text { Succinic Acid } \\
\text { Mono-Methyl } \\
\text { Ester }(0 \%)\end{array}$ & \begin{tabular}{|l|} 
F8 \\
Propionic Acid \\
$(0 \%)$
\end{tabular} & $\begin{array}{l}\text { F9 } \\
\text { Pyruvic Acid } \\
(0 \%)\end{array}$ & \begin{tabular}{|l} 
F10 \\
Succinamic \\
Acid $(0 \%)$
\end{tabular} & $\begin{array}{l}\text { F11 } \\
\text { Succinic Acid } \\
(0 \%)\end{array}$ & \begin{tabular}{|l} 
F12 \\
N-Acetyl \\
-L-Glutamic \\
Acid $(0 \%)$
\end{tabular} \\
\hline G & \begin{tabular}{|l|} 
G1 \\
L- \\
Alaninamide \\
$(0 \%)$ \\
\end{tabular} & \begin{tabular}{|l} 
G2 \\
D-Alanine \\
$(0 \%)$
\end{tabular} & $\begin{array}{l}\text { G3 } \\
\text { L-Alanine } \\
(0 \%)\end{array}$ & \begin{tabular}{|l|} 
G4 \\
L-Alanyl- \\
glycine $(0 \%)$
\end{tabular} & \begin{tabular}{|l|} 
G5 \\
L- \\
Asparagine \\
$(0 \%)$ \\
\end{tabular} & $\begin{array}{l}\text { G6 } \\
\text { L-Glutamic } \\
\text { Acid } \\
(0 \%) \\
\end{array}$ & $\begin{array}{l}\text { G7 } \\
\text { Glycyl-L- } \\
\text { Glutamic Acid } \\
(0 \%) \\
\end{array}$ & \begin{tabular}{|l|} 
G8 \\
L-Pyroglutamic \\
Acid $(0 \%)$
\end{tabular} & \begin{tabular}{|l|} 
G9 \\
L-Serine \\
$(0 \%)$
\end{tabular} & $\begin{array}{l}\text { G10 } \\
\text { Putrescine } \\
(0 \%)\end{array}$ & $\begin{array}{l}\text { G11 } \\
2,3- \\
\text { Butanediol } \\
(0 \%)\end{array}$ & \begin{tabular}{|l|} 
G12 \\
Glycerol \\
$(0 \%)$
\end{tabular} \\
\hline $\mathrm{H}$ & \begin{tabular}{|l}
$\mathrm{H} 1$ \\
Adenosine \\
$(100 \%)$
\end{tabular} & \begin{tabular}{|l} 
H2 \\
2'-Deoxy \\
Adenosine \\
$(61.5 \%)$
\end{tabular} & $\begin{array}{l}\mathrm{H} 3 \\
\text { Inosine } \\
(92.3 \%)\end{array}$ & \begin{tabular}{|l|} 
H4 \\
Thymidine \\
$(92.3 \%)$
\end{tabular} & \begin{tabular}{|l} 
H5 \\
Uridine \\
$(92.3 \%)$
\end{tabular} & \begin{tabular}{|l|} 
H6 \\
A denosine-5'- \\
Monophosphat \\
e \\
$(53.8 \%)$
\end{tabular} & $\begin{array}{l}\text { H7 } \\
\text { Thymidine-5'- } \\
\text { Monophosphate } \\
(0 \%)\end{array}$ & \begin{tabular}{|l|} 
H8 \\
Uridine-5'- \\
Monophosphat \\
e \\
$(53.8 \%)$
\end{tabular} & \begin{tabular}{|l} 
H \\
D-Fructose \\
$-6-$ Phosphate \\
$(0 \%)$
\end{tabular} & \begin{tabular}{|l|} 
H10 \\
a-D-Glucose- \\
1-Phosphate \\
$(0 \%)$
\end{tabular} & $\begin{array}{l}\text { H11 } \\
\text { D-Glucose-6- } \\
\text { Phosphate } \\
(0 \%)\end{array}$ & \begin{tabular}{|l|} 
H12 \\
D-L- $\alpha-$ \\
Glycerol \\
Phosphate \\
$(0 \%)$
\end{tabular} \\
\hline
\end{tabular}

Fig. 1 Percent of positive profiles for Enterococcus cecorum in Biolog GP2 MicroPlate ${ }^{\mathrm{TM}}$

Table 4 Antibiotics resistance patterns of E. cecorum strains isolated from clinical cases of different bird species

\begin{tabular}{ll}
\hline Antibiotics ( $n$, number of antibiotics) & $\%(n)$ of resistant isolates \\
\hline ENF/E/T/DXT/TEC (5) & $2.5(2)$ \\
ENF/E/T/DXT (4) & $33.3(27)$ \\
ENF/T/DXT/TEC (4) & $1.2(1)$ \\
ENF/T/DXT/AP (4) & $1.2(1)$ \\
ENF/T/DXT (3) & $33.3(27)$ \\
T/E/DXT (3) & $4.9(4)$ \\
ENF/E/T (3) & $2.5(2)$ \\
ENF/E/GM (3) & $1.2(1)$ \\
ENF/DXT/NA (3) & $1.2(1)$ \\
T/DXT (2) & $6.2(5)$ \\
ENF/E (2) & $2.5(2)$ \\
ENF/TEC (2) & $1.2(1)$ \\
T/TEC (2) & $1.2(1)$ \\
ENF (1) & $7.4(6)$ \\
0 & $1.2(1)$ \\
\hline
\end{tabular}

Ampicillin (AP $10 \mu \mathrm{g}$ ), enrofloxacin (ENF $5 \mu \mathrm{g}$ ), tetracycline (TEC $30 \mu \mathrm{g}$ ), Doxycycline (DXT $30 \mu \mathrm{g}$ ), erythromycin (E $15 \mu \mathrm{g})$, teicoplanin (T $30 \mu \mathrm{g}$ ), Vancomycin (VA $30 \mu \mathrm{g})$, high level gentamicin (GM $120 \mu \mathrm{g}$ )
$30 \mathrm{~min}$. The results may indicate to the possibly longer survival E. cecorum at more extreme temperatures in the poultry house environment.

We confirmed the efficacy of two biochemical systems for identification poultry-origin E. cecorum strains. Instead of doubtful or unacceptable profile in API, all strains were properly recognized by sodA gene sequencing. We found, that almost all clinical strains gave positive reactions in 10 biochemical tests, and negative in 5 tests (API). Similar results were reported for other $E$. cecorum including commensal or reference strains with some exceptions $[1,17,28,32]$. We observed that all of strains were able to metabolise $\alpha$-cyclodextrin. Makrai et al. [10] observed differences among clinical isolates in metabolism of both $\alpha$ - and $\beta$-cyclodextrin. We noted relatively high positive reactions for $\beta G A L, \beta G A R, V P$, opposed to reference $E$. cecorum strain and despite the discrepancies in the literature [17]. In contrast to other studies [2,17], some clinical E. cecorum showed ability to produce urease, $\beta$-mannosidase, and metabolize glycogen. On the other hand, results for $\beta$ mannosidase, glycogen, mannitol were lower for clinical isolates than reported for standard strains. Our results were consistent with Borst et al. [33] who noted that pathogenic E. cecorum isolates are more deficient in mannitol metabolism. Recently molecular aspects for the defect mannitol metabolism in pathogenic strains were investigated [34]. 


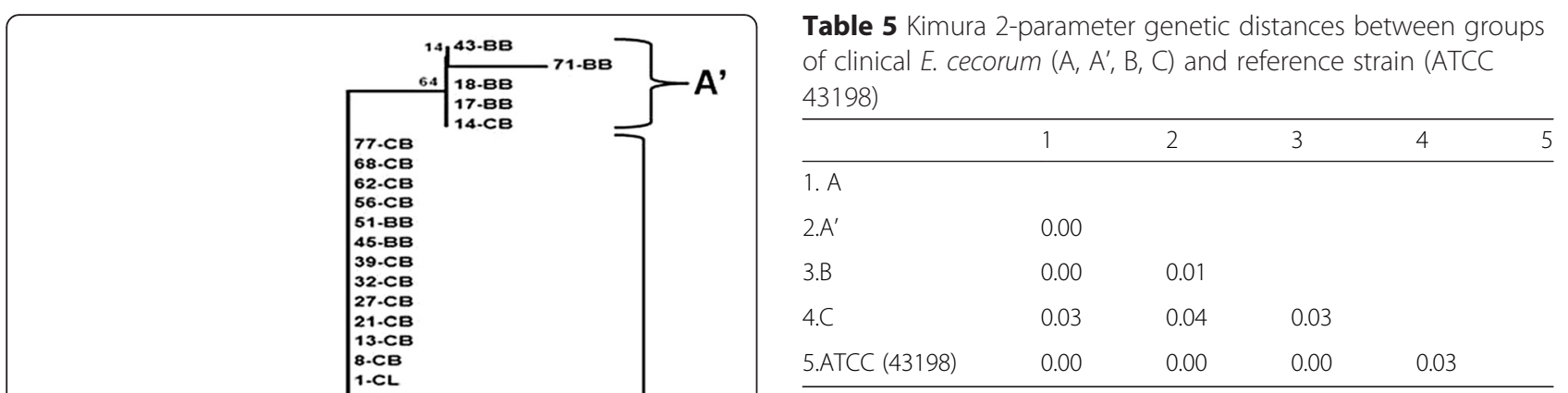

Based on comparative analysis of our results with study of Makrai et al. [10], it could be assumed, that all clinical E. cecorum may metabolise 18 carbon sources (adenosine, arbutin, D-cellobiose, dextrin, Dfructose, D-mannose, D-psicose, D-raffinose, D-trehalose, gentiobiose, maltose, maltotriose, N-acetyl-D-glucosamine, $\mathrm{N}$-acetyl- $\beta$-D-mannosamine, pyruvic acid methyl ester, salicin, sucrose, $\alpha$-D-glucose). Similarly to above mentioned authors, clinical isolates may give differences in 3 tests: $\alpha$-D-lactose, D-ribose, 2deoxy adenosine.

Recently several potential mediators of virulence were found in pathogenic E. cecorum isolated from chickens in the southeast US. These virulence determinants conserved in pathogenic EC were found to be similar to those utilized by other medically important enterococci [33]. In the present study, only $32.9 \%$ clinical $E$. cecorum strains contained one or more virulence genes. E. cecorum from chicken flocks contained mainly asa1/ gelE/ace genes. The pathogenicity of E. cecorum may be associated with other species-specific virulence factors. Similar observations were presented by Jackson et al. [35] who detected only few virulence genes among US E. cecorum isolates, and the incidences of virulence determinants tested were lower than ours. In our study the most of positive isolates contained two asa1/gelE or four asal/gelE/efaA/ace virulence genes. We speculated about possible linkage between asa1/gelE ( $74 \%$ of all virulence positive isolates) or efaAlace (33.3\% of all virulence positive isolates) in clinical E. cecorum. It may have impact on pathogenesis and clinical course of infection.

Because none of the investigated strains harbored hyl

Fig. 2 Phylogenetic tree constructed using the Neighbor-Joining algorithm to evaluate the distance between partial sodA gene sequences of 82 clinical Enterococcus cecorum poultry-origin strains and E. cecorum reference strain (ATCC 43198). The bootstrap values (1000 replicates) are reported as percentage greater than $60 \%$. The evolutionary distances were computed using the Kimura 2-parameter method and are in the units of the number of base substitutions per site. Evolutionary analyses were conducted in MEGA6 gene, we suggest that this virulence determinant may be not widespread among clinical isolates. Our results were consistent with other authors who described the lack of $h y l$ in E. cecorum from poultry carcass rinsates, diseased chickens [35] and pigeons [5]. According to the literature, hyaluronidase is a degradative enzyme that is associated with tissue damage. Among Enteroccocus species the $h y l$ gene has been reported more often in ampicillinresistant VRE E. faecium isolates [36]. We suggest that 
Table 6 Twenty one PFGE profiles (A-U) of clinical isolates E. cecorum derived from poultry in Poland between 2011-2014

\begin{tabular}{|c|c|c|c|c|c|c|}
\hline Pulsotype & Poultry type & No. of strain & Year & Poland's voivodeship & Number of isolates of each pulsotype & \% Similarity (>80 \%) \\
\hline \multirow[t]{2}{*}{ A } & $C B$ & 76 & 2014 & Greater Poland & 2 & 84.2 \\
\hline & $C B$ & 39 & 2014 & Greater Poland & & \\
\hline \multirow[t]{2}{*}{ B } & $C B$ & 32 & 2014 & Greater Poland & 2 & 92.3 \\
\hline & $C B$ & 31 & 2013 & Świętokrzyskie & & \\
\hline \multirow[t]{2}{*}{ C } & $C B$ & 3 & 2011 & Greater Poland & 2 & 84.2 \\
\hline & $\mathrm{CB}$ & 23 & 2012 & Silesian & & \\
\hline \multirow[t]{2}{*}{ D } & $C B$ & 80 & 2014 & Masovian & 2 & 81.8 \\
\hline & $C B$ & 57 & 2014 & Masovian & & \\
\hline \multirow[t]{4}{*}{ E } & $\mathrm{BB}$ & 60 & 2014 & Warmian-Masurian & 4 & 85.7 \\
\hline & $C B$ & 52 & 2014 & Pomeranian & & \\
\hline & $C B$ & 47 & 2014 & Greater Poland & & \\
\hline & $C B$ & 27 & 2013 & Greater Poland & & \\
\hline \multirow[t]{3}{*}{$\mathrm{F}$} & $C B$ & 81 & 2014 & Masovian & 3 & 84.2 \\
\hline & $\mathrm{CB}$ & 53 & 2014 & Pomeranian & & \\
\hline & $C B$ & 34 & 2014 & Greater Poland & & \\
\hline \multirow[t]{2}{*}{ G } & BB & 46 & 2014 & Masovian & 2 & 87.0 \\
\hline & $C B$ & 2 & 2011 & Greater Poland & & \\
\hline \multirow[t]{2}{*}{$\mathrm{H}$} & $\mathrm{CL}$ & 44 & 2014 & Podlaskie & 2 & 84.6 \\
\hline & $C B$ & 28 & 2013 & Greater Poland & & \\
\hline \multirow[t]{2}{*}{ । } & $C B$ & 82 & 2014 & Masovian & 2 & 81.2 \\
\hline & $\mathrm{BB}$ & 66 & 2014 & Opolskie & & \\
\hline \multirow[t]{3}{*}{ J } & $\mathrm{BB}$ & 67 & 2014 & Masovian & 3 & 80.1 \\
\hline & $\mathrm{BB}$ & 48 & 2014 & Masovian & & \\
\hline & $\mathrm{CL}$ & 4 & 2011 & Greater Poland & & \\
\hline \multirow[t]{3}{*}{ K } & $C B$ & 42 & 2014 & Pomeranian & 3 & 80.8 \\
\hline & $C B$ & 40 & 2014 & Pomeranian & & \\
\hline & $\mathrm{CB}$ & 21 & 2012 & Warmian-Masurian & & \\
\hline \multirow[t]{4}{*}{ L } & $C B$ & 70 & 2014 & Masovian & 4 & 84.3 \\
\hline & $\mathrm{CB}$ & 62 & 2014 & Masovian & & \\
\hline & $C B$ & 61 & 2014 & Masovian & & \\
\hline & $C B$ & 20 & 2014 & Masovian & & \\
\hline \multirow[t]{8}{*}{ M } & $C B$ & 77 & 2014 & Kuyavian-Pomeranian & 8 & 82.1 \\
\hline & $C B$ & 56 & 2014 & Greater Poland & & \\
\hline & $C B$ & 35 & 2014 & Greater Poland & & \\
\hline & $C B$ & 25 & 2014 & Pomeranian & & \\
\hline & $C B$ & 58 & 2014 & Pomeranian & & \\
\hline & $\mathrm{CB}$ & 75 & 2014 & Lodzkie & & \\
\hline & BB & 51 & 2014 & West Pomeranian & & \\
\hline & $\mathrm{BB}$ & 55 & 2014 & West Pomeranian & & \\
\hline \multirow[t]{3}{*}{ N } & $\mathrm{CB}$ & 68 & 2014 & Masovian & 3 & 84.0 \\
\hline & $\mathrm{CL}$ & 65 & 2014 & Masovian & & \\
\hline & $C B$ & 13 & 2011 & Greater Poland & & \\
\hline \multirow[t]{2}{*}{ O } & $C B$ & 30 & 2013 & Masovian & 3 & 81.8 \\
\hline & $C B$ & 19 & 2011 & Świętokrzyskie & & \\
\hline
\end{tabular}


Table 6 Twenty one PFGE profiles (A-U) of clinical isolates E. cecorum derived from poultry in Poland between 2011-2014 (Continued)

\begin{tabular}{|c|c|c|c|c|c|c|}
\hline & $\mathrm{CL}$ & 10 & 2011 & Greater Poland & & \\
\hline \multirow[t]{2}{*}{$P$} & $\mathrm{CB}$ & 78 & 2014 & Greater Poland & 2 & 86.7 \\
\hline & $\mathrm{CB}$ & 37 & 2014 & Greater Poland & & \\
\hline \multirow[t]{2}{*}{ Q } & $\mathrm{BB}$ & 45 & 2014 & West Pomeranian & 2 & 81.3 \\
\hline & $C B$ & 11 & 2011 & Greater Poland & & \\
\hline \multirow[t]{2}{*}{$\mathrm{R}$} & $\mathrm{BB}$ & 71 & 2014 & Masovian & 2 & 81.5 \\
\hline & $C B$ & 14 & 2011 & Greater Poland & & \\
\hline \multirow[t]{2}{*}{$S$} & G & 29 & 2013 & Greater Poland & 2 & 90.3 \\
\hline & $C B$ & 22 & 2012 & Pomeranian & & \\
\hline \multirow[t]{4}{*}{$\mathrm{T}$} & $\mathrm{BB}$ & 59 & 2014 & Warmian-Masurian & 4 & 84.1 \\
\hline & $\mathrm{CL}$ & 6 & 2011 & Greater Poland & & \\
\hline & $C B$ & 16 & 2011 & Greater Poland & & \\
\hline & $C B$ & 24 & 2012 & Masovian & & \\
\hline \multirow[t]{3}{*}{$U$} & $\mathrm{CL}$ & 1 & 2012 & Greater Poland & 3 & 87.0 \\
\hline & $\mathrm{CL}$ & 5 & 2012 & Greater Poland & & \\
\hline & $\mathrm{CL}$ & 7 & 2011 & Greater Poland & & \\
\hline
\end{tabular}

$h y l$ is not specific for E. cecorum and could has minor role in pathogenicity of $E$. cecorum, however more studies are needed to elucidate this aspect.

The present study showed lack of correlation between the presence of gelE gene and its expression. The literature provide no data in regard this aspect on E. cecorum, however similar observations are available for E. faecalis [37].

Generally, pathogenic isolates from poultry were found to be significantly more drug resistant than commensal strains [33]. In the present study almost all of clinical isolates showed high level of antibiotic resistance and $91.5 \%$ of them showed multidrug resistance (resistance to $\geq 2$ antimicrobials). Other authors identified lower multidrug resistance in E. cecorum from carcass rinsates and diseased poultry, however the panel of used antibicrobials were not completely the same [35]. Affected flocks were treated against E. cecorum usually with amoxicillin, doxycycline or enrofloxacin. All of the above antibiotics were tested in this study. Similarly to other authors, the overwhelming majority of the isolates were susceptible to penicillin, which appear to be drug of choice $[4,5,7,10,14,15]$. However, the majority of $E$. cecorum was resistant to enrofloxacin $>$ teicoplanin $>$ doxycycline > erythromycin. Our results were opposed to clinical E. cecorum from other countries, in which sensitivity to enrofloxacin (in Germany, Holland, Hungary, South Africa), doxycycline (in Germany, Hungary) and macrolides (in Belgium, Germany) were identified $[4,5,7,10,14,15]$. Similarly to the isolates from Canada, USA, Holland and Belgium, clinical $E$. cecorum from Poland showed the increased resistance to tetracycline or erythromycin (macrolides) [4, 7, 27, 33, 35].
This antimicrobial resistance pattern may be common and characteristic for pathogenic E. cecorum. The presented study indicated on the presence clinical E. cecorum (1.2 \%) with the resistance to vancomycin (VRE) and to high level gentamicin (HLGR). Similarly to Jackson et al. [35], we found out that none of the isolates were resistant to linezolid. According to the literature, enterococci have both an intrinsic and acquired resistance to antibiotics which complicate treatment of infections. The acquired resistance includes resistance to i.a. chloramphenicol, tetracyclines, fluoroquinolones, aminoglycosides (high levels), and vancomycin. Enterococci have demonstrated a huge potential for acquiring and disseminating resistant genes. We found, that the high level of the resistance to enrofloxacin, doxycycline, tetracycline in E. cecorum isolates is probably related to the wide use of these antibiotics in poultry production. In previous years erythromycin was also commonly applied in the therapy of poultry. Other authors confirmed the presence of resistance genes (including van genes) among E. cecorum from broilers or retail chicken meat $[38,39]$. We suggest, that poultry may play an important role as reservoirs of antibiotic resistant E. cecorum in the environment. However, further studies are needed to investigate the resistance genes in clinical isolates.

In the present study sodA gene fragment was successfully used to confirm phenotypic identification of $E$. cecorum, however it was not sufficiently discriminative to differentiate them from each other. In the collection it was possible to distinguish for three phylogenetic groups and one subgroup. The strains from group $\mathrm{B}$ showed the same type of production (CB), year of 


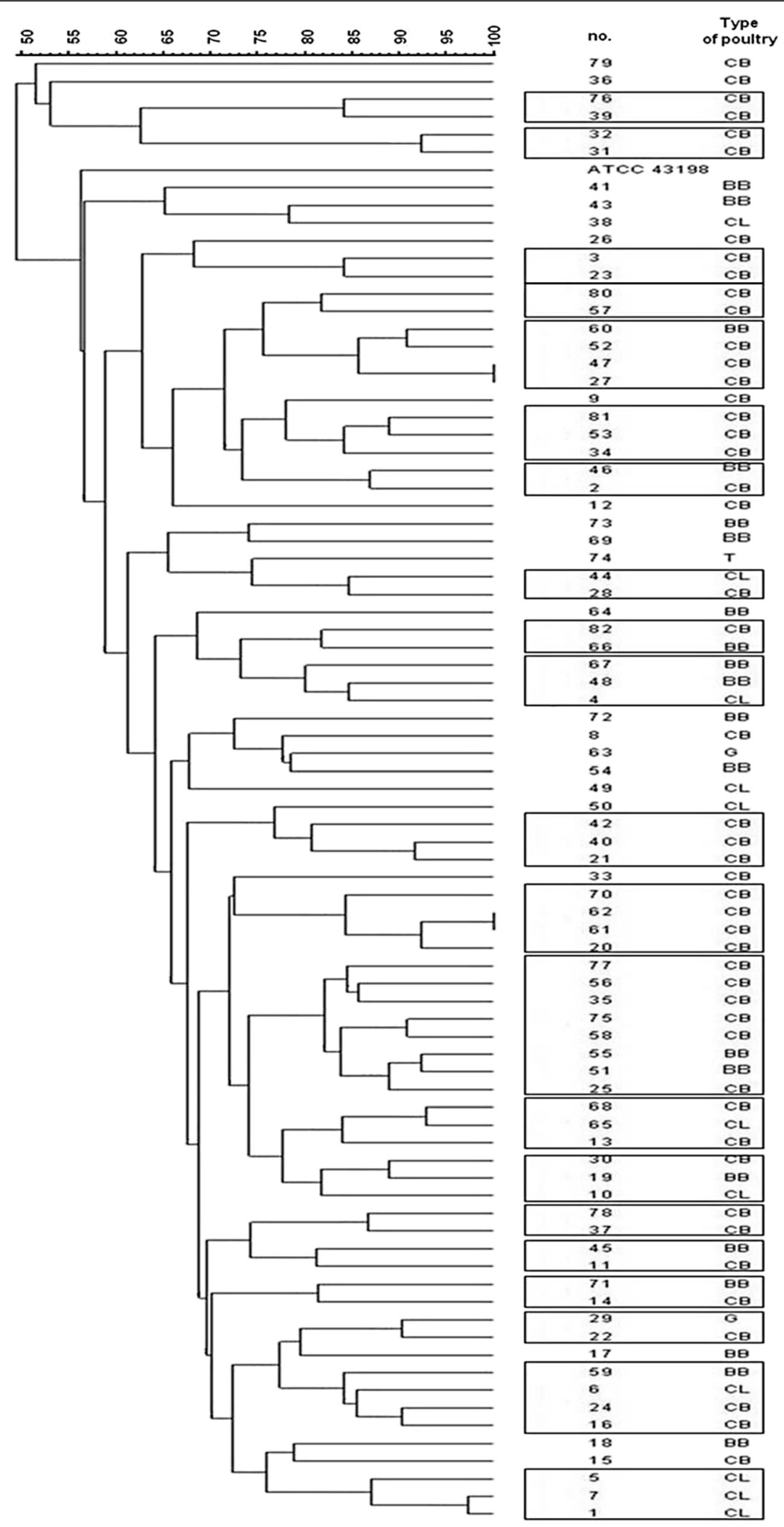

Fig. 3 Results of pulsed field gel electrophoresis (PFGE) examination of Enterococcus cecorum clinical isolates. Dendrogram based on Dice coefficient with $1 \%$ position tolerance. Cut-off value of $80 \%$ similarity was used to assign the pulsotypes 
isolation, virulence determinants and multidrug resistance pattern, but different geographical origin; $80 \%$ of them belong to pulsotype $\mathrm{M}$. The strains of group $\mathrm{C}$ shared only the same year of isolation, virulence and multidrug resistance patterns. The low genetic distance (based on $\operatorname{sodA}$ gene sequences) indicated on the very close genetic relationships between clinical E. cecorum. No clear genetic differences were observed between clinical strains and reference strain.

Recent data indicated that pathogenic E. cecorum from the southeast US were clonal, however comparative genomic analysis revealed fundamental differences in their genomes [34]. According to the previous report, isolates recovered from spinal abscesses were highly similar and could be detected by using PFGE [33]. In our study, PFGE results showed the genetic heterogeneity between clinical E. cecorum isolates, that is consistent with the other studies [18]. Therefore, the usage of PFGE in distinguishing pathogenic strains may be difficult and limited. This genetic diversity was seen between poultry flocks, however some clustering was visible in relation of type of production $(\mathrm{CB}, \mathrm{CL})$. Moreover, some temporal and geographical clustering was visible. Many $\mathrm{CB}$ isolates from the same year and geographical origin were clustered together (pulsotype A, D, L, P) indicating their close genetic relationship. Some CL isolates from the same location but different years were grouped into a single pulsotype (U) indicating on the possible horizontal transmission among CL flocks in this area. We found that $\mathrm{CB}$ and $\mathrm{BB}$ isolates from the same year which were clustered together into separate pulsotypes (I, M). Based on the relatively close relationship between isolates from geese and chicken flocks, it could be assumed that isolates from the single clonal lineage may cause outbreaks in different bird species. The results may suggest the transmission of potential diseasecausing E. cecorum between flocks.

\section{Conclusions}

These data indicate that several, widely distributed pathogenic E. cecorum clones seemed to be responsible for infection cases found in different poultry types. The isolates causing infection in different CB flock in the same year and region may be somewhat genetically distinct from each other and from those that cause disease in $\mathrm{CL}$ or BB flocks in the same year and region. Phenotypically, clinical isolates were generally found to be very similar, however some properties or characteristics described in some isolates were not found in others. The study presented here is the first in Poland as well as one of the few in Europe which provides phenotypic and genotypic characterization of $E$. cecorum isolates associated with disease outbreaks in poultry flocks. Further research needs to focus on finding new virulence determinants of E. cecorum and recognition of transmission routes.

\section{Additional files}

Additional file 1: Alignment of partial sodA gene sequences from $E$. cecorum isolates and reference strain (ATCC 43198). Nucleotide differences are specified by the nucleotide, while dot represented no nucleotide changing. (TIF $12403 \mathrm{~kb}$ )

Additional file 2: Alignment of partial 16S rRNA gene sequences from E. cecorum isolates and reference strain (ATCC 43198). Nucleotide differences are specified by the nucleotide, while dot represented no nucleotide changing. (TIF $60654 \mathrm{~kb}$ )

\section{Abbreviations}

BB, broiler breeder flocks; CA, Columbia agar with $5 \%$ sheep blood; CB, chicken broiler flocks (commercial broilers); $\mathrm{CL}$, commercial layer flocks; $E$. cecorum, Enterococcus cecorum; ES, enterococcal spondylitis; G, geese flocks; HLGR, high level gentamicin resistance; PFGE, Pulsed Field Gel

Electrophoresis; T, turkey flock; VRE Vancomycin-Resistant Enterococcus

\section{Acknowledgements}

The authors thank mgr Beata Sienkiewicz for excellent technical assistance. The authors are very grateful veterinary laboratories and private practice veterinarians for help in collecting strains: Microbiological Laboratory SGGW, SLW Biolab Ostróda, Lab-Vet Sp. z o.o. Tarnowo Podgórne, Vet-Lab Brudzew, Vetdiagnostica Solec Kujawski, Animal Pharma, Wet-Net s.c. Giżycko, Gabinet Weterynaryjny "Gallus" Sylwester Barabasz, "Spec-Drób" Mariusz Lorek, and DVM: Anna Biegańska, Magdalena Wiczk, Tomasz Nowak, Ismaila Massaly, Mirosław Berezowski, Paweł Tubielewicz, Natalia Bednarz.

\section{Funding}

This work was financially supported by grant no. 505-10-023700-L00183-99 at Department of Pathology and Veterinary Diagnostics, Faculty of Veterinary Medicine, Warsaw University of Life Sciences-SGGW, Poland. The analysis by Biolog system was supported by Department of Microbiology and Infectious Diseases, Faculty of Veterinary Science, Szent István University in Budapest, Hungary.

\section{Availability of data and material}

The datasets supporting our findings are included within the article and its Additional files 1 and 2 .

\section{Authors' contributions}

$\mathrm{BD}$ conceived and designed the study, collected the strains, performed all works, analysis and interpretation of data, wrote manuscript. DCC input in PFGE. LM contributed to perform analysis in Biolog system. PS gave conceptual advice and additional inputs in study project, contributed materials. All authors read and approved the final manuscript.

\section{Competing interests}

The authors declare that they have no competing interests.

\section{Consent to publication}

Not applicable.

\section{Ethics approval and consent to participate}

Poultry samples were collected for laboratory diagnosis by as part of the usual clinical practice on farms, and Polish ethical guidelines (Dz.U. 2015 poz. 266) and animal welfare regulations were strictly respected. Veterinarians who provided healthcare for poultry flocks were in contact with the owners, and gave an oral informed consent and acceptance for using obtained isolates for research studies. As this study was focused on bacterial isolates collected from routine samples, approval from Ethics Committee at the Warsaw University of Life Sciences University was not necessary.

\section{Author details}

${ }^{1}$ Department of Pathology and Veterinary Diagnostics, Faculty of Veterinary Medicine, Warsaw University of Life Sciences-SGGW, Nowoursynowska 159c St., Warsaw 02-776, Poland. ²Department of Preclinical Sciences, Faculty of Veterinary Medicine, Warsaw University of Life Sciences-SGGW, Ciszewskiego 8 St., Warsaw 02-786, Poland. ${ }^{3}$ Department of Microbiology and Infectious Diseases, Faculty of Veterinary Science, Szent István University, Hungária krt. 23-25, Budapest $\mathrm{H}-1143$, Hungary. 
Received: 6 February 2016 Accepted: 23 June 2016

Published online: 27 June 2016

\section{References}

1. Devriese LA, Dutta GN, Farrow JAE, van de Kerckhove A, Phillips BA. Streptococcus cecorum, a new species isolated from chickens. Int J Syst Bacteriol. 1983;33:772-6.

2. Greub G, Devriese LA, Pot B, Dominguez J, Bille J. Enterococcus cecorum septicemia in a malnourished adult patient. Eur J Clin Microbiol Infect Dis. 1997; 16:594-8

3. Warnke P, Köller T, Stoll P, Podbielski A. Nosocomial infection due to Enterococcus cecorum identified by MALDI-TOF MS and Vitek 2 from a blood culture of a septic patient. Eur J Microbiol Immunol (Bp). 2015:5:177-9.

4. Devriese LA, Cauwerts K, Hermans K, Wood AM. Enterococcus cecorum septicaemia as a cause of bone and joint lesions resulting in lameness in broiler chickens. Flemish Vet J. 2002;71:219-21.

5. Jung A, Teske L, Rautenschlein S. Enterococcus cecorum infection in a racing pigeon. Avian Dis. 2014;58:654-8

6. Wood AM, MacKenzie G, McGiliveray NC, Brown L, Devriese LA, Baele M. Isolation of Enterococcus cecorum from bone lesions in broiler chickens. Vet Rec. 2002;150:27

7. De Herdt P, Defoort P, Van Steelant J, Swam H, Tanghe L, Van Goethem S, Vanrobaeys M. Enterococcus cecorum osteomyelitis and arthritis in broiler chickens. Vlaams Diergen Tijds. 2008;78:44-8.

8. Stalker MJ, Brash ML, Weisz A, Ouckama RM, Slavic D. Arthritis and osteomyelitis associated with Enterococcus cecorum infection in broiler and broiler breeder chickens in Ontario, Canada. J Vet Diagn Invest. 2010;22: 643-5.

9. Armour NK, Collett SR, Williams SM. Enterococcus cecorum - related arthritis and osteomyelitis in broilers and broiler breeders. Poult Inf Profess. 2011;17:1-7.

10. Makrai L, Nemes C, Simon A, Ivanics E, Dudás Z, Fodor L, Glávits R. Association of Enterococcus cecorum with vertebral osteomyelitis and spondylolisthesis in broiler parent chicks. Acta Vet Hung. 2011:59:11-21.

11. Dolka B, Szeleszczuk P. Enterococcal vertebral osteoarthritis in chickens. Med Weter. 2012:68:157-62

12. Robbins KM, Suyemoto MM, Lyman RL, Martin MP, Barnes HJ, Borst LB. An outbreak and source investigation of enterococcal spondylitis in broilers caused by Enterococcus cecorum. Avian Dis. 2012;56:768-73.

13. Szeleszczuk P, Dolka B, Żbikowski A, Dolka I, Peryga M. First case of enterococcal spondylitis in broiler chickens in Poland. Med Weter. 2013;69: 298-303.

14. Aitchison H, Poolman P, Coetzer M, Griffiths C, Jacobs J, Meyer M, Bisschop S. Enterococcal-related vertebral osteoarthritis in South African broiler breeders: A case report. J S Afr Vet Assoc. 2014:85:1077.

15. Jung A, Rautenschlein S. Comprehensive report of an Enterococcus cecorum infection in a broiler flock in Northern Germany. BMC Vet Res. 2014:10:311.

16. Murray BE. The life and times of the Enterococcus. Clin Microbiol Rev. 1990;3: 46-65.

17. Manero A, Blanch AR. Identification of Enterococcus spp. with a biochemical key. Appl Environ Microbiol. 1999;65:4425-30.

18. Wijetunge DS, Dunn P, Wallner-Pendleton E, Lintner V, Lu H, Kariyawasam S. Fingerprinting of poultry isolates of Enterococcus cecorum using three molecular typing methods. J Vet Diagn Invest. 2012;24:1166-71.

19. Tenover FC, Arbeit RD, Goering RV, Mickelsen PA, Murray BE, Persing DH Swaminathan B. Interpreting chromosomal DNA restriction patterns produced by pulsed-field gel electrophoresis: criteria for bacterial strain typing. J Clin Microbiol. 1995:33:2233-9.

20. Kense MJ, Landman WJ. Enterococcus cecorum infections in broiler breeders and their offspring: molecular epidemiology. Avian Pathol. 2011:40:603-12

21. Ke D, Picard FJ, Martineau F, Menard C, Roy PH, Ouellette M, Bergeron MG. Development of a PCR assay for rapid detection of enterococci. J Clin Microbiol. 1999;37:3497-503.

22. Jackson CR, Fedoka - Cray PJ, Barett JB. Use of a genus- and species-specific multiplex PCR for identication of enterococci. J Clin Microbiol. 2004;42: 3558-65.

23. Tsai JC, Hsueh PR, Lin HM, Chang HJ, Ho SW, Teng LJ. Identification of clinically relevant enterococcus species by direct sequencing of groES and spacer region. J Clin Microbiol. 2005:43:235-41.

24. Martín-Platero AM, Valdivia E, Maqueda M, Martínez-Bueno M. Characterization and safety evaluation of enterococci isolated from Spanish goats' milk cheeses. Int J Food Microbiol. 2009;132:24-32.
25. CLSI. Performance Standards for Antimicrobial Disk and Dilution Susceptibility Tests for Bacteria Isolated from Animals; Approved Standard Fourth Edition. Wayne: Clinical and Laboratory Standards Institute; 2013. PA CLSI document VET01-A4, supplement VET01-S2.

26. Van den Braak $N$, van Belkum $A$, van Keulen $M$, Vliegenthart J, Verbrugh $H A$, Endtz HP. Molecular characterization of vancomycin-resistant enterococci from hospitalized patients and poultry products in The Netherlands. J Clin Microbiol. 1998;36:1927-32.

27. Boerlin P, Nicholson V, Brash M, Slavic D, Boyen F, Sanei B, Butaye P. Diversity of Enterococcus cecorum from chickens. Vet Microbiol. 2012;157: 405-11.

28. Devriese LA, Hommez J, Wijfels R, Haesebrouck F. Composition of the enterococcal and streptococcal intestinal flora of poultry. J Appl Bacteriol. 1991;71:46-50

29. Devriese LA, Pot B, Collins MD. Phenotypic identification of the genus Enterococcus and differentiation of phylogenetically distinct enterococcal species and species groups. J Appl Bacteriol. 1993;75:399-408.

30. Domig KJ, Mayer HK, Kneifel W. Methods used for the isolation, enumeration, characterisation and identification of Enterococcus spp. 2. Pheno- and genotypic criteria. Int J Food Microbiol. 2003;55:165-88.

31. Fisher K, Phillips C. The ecology, epidemiology and virulence of Enterococcus. Microbiology. 2009:155:1749-57.

32. Devriese LA, Ceyssens K, Haesebrouck F. Characteristics of Enterococcus cecorum strains from the intestines of different animal species. Lett Appl Microbiol. 1991;12:137-9.

33. Borst LB, Suyemoto MM, Robbins KM, Lyman RL, Martin MP, Barnes HJ. Molecular epidemiology of Enterococcus cecorum isolates recovered from enterococcal spondylitis outbreaks in the southeastern United States. Avian Pathol. 2012;41:479-85.

34. Borst LB, Suyemoto MM, Scholl EH, Fuller FJ, Barnes HJ. Comparative genomic analysis identifies divergent genomic features of pathogenic Enterococcus cecorum including a type IC CRISPR-Cas system, a capsule locus, an epa-like locus, and putative host tissue binding proteins. PLoS One. 2015;10:e0121294.

35. Jackson CR, Kariyawasam S, Borst LB, Frye JG, Barrett JB, Hiott LM, Woodley TA. Antimicrobial resistance, virulence determinants and genetic profiles of clinical and nonclinical Enterococcus cecorum from poultry. Lett Appl Microbiol. 2015;60:111-9.

36. Vankerckhoven V, Van Autgaerden T, Vael C, Lammens C, Chapelle S, Rossi $R$, Jabes $D$, Goossens $H$. Development of a multiplex PCR for the detection of asa1, gelE, cylA, esp, and hyl genes in enterococci and survey for virulence determinants among European hospital isolates of Enterococcus faecium. J Clin Microbiol. 2004;42:4473-9.

37. Olsen $\mathrm{RH}$, Schønheyder HC, Christensen H, Bisgaard M. Enterococcus faecalis of human and poultry origin share virulence genes supporting the zoonotic potential of E. faecalis. Zoonoses Public Health. 2012;59:256-63.

38. Cauwerts K, Decostere A, De Graef EM, Haesebrouck F, Pasmans F. High prevalence of tetracycline resistance in Enterococcus isolates from broilers carrying the erm(B) gene. Avian Pathol. 2007;36:395-9.

39. Harada T, Kawahara R, Kanki M, Taguchi M, Kumeda Y. Isolation and characterization of vanA genotype vancomycin-resistant Enterococcus cecorum from retail poultry in Japan. Int J Food Microbiol. 2012;153:372-7.

\section{Submit your next manuscript to BioMed Central and we will help you at every step:}

- We accept pre-submission inquiries

- Our selector tool helps you to find the most relevant journal

- We provide round the clock customer support

- Convenient online submission

- Thorough peer review

- Inclusion in PubMed and all major indexing services

- Maximum visibility for your research

Submit your manuscript at www.biomedcentral.com/submit 